\title{
Demographic and Social-Economic Determinants of Malnutrition among Children (0-23 Months Old) in Kenya
}

\author{
Teresia Mbogori ${ }^{1, *}$ and James Muriuki ${ }^{2}$ \\ ${ }^{1}$ Department of Nutrition and Health Science, HB 542, Ball State University, Muncie, IN 47306, USA; \\ ${ }^{2}$ Department of Agricultural and Applied Economics, Texas Tech University, Lubbock TX, USA
}

\begin{abstract}
Objective: To identify the demographic, social, and economic determinants of malnutrition in Kenya's children aged 0-23 months.

Methods: Data from the Kenya Demographic and Health Survey (KDHS), a nationally representative cross-sectional study conducted in 2014/2015, were used in this study. Data from children 0-23 months old with complete information on weight, height, age, and sex were used for analysis. Height for Age Z scores (HAZ), Weight for Height Z scores (WHZ), and $\mathrm{BMI}$ for age $Z$ scores (BAZ) was determined using WHO guidelines to determine the nutritional status of the children. Chi-square statistics were used to determine the relationship between social-economic status and place of residence indicators and the nutritional status of the children. Significance was set at $p<0.05$.

Results: Among all participating ( $\mathrm{n}=7578), 22.7 \%$ were stunted (HAZ $<-2), 6.2 \%$ were wasted $(\mathrm{WHZ}<-2)$, and $6.1 \%$ were either overweight or obese (BAZ > 2). Wasting and stunting were significantly higher in children from rural areas, poorer wealth index, and mothers with no education. In contrast, children from urban areas, the richest wealth index category, and mothers with secondary or higher education were significantly more likely to be overweight or obese.

Conclusion: Current and future policies and programs to curb malnutrition in Kenya need to target specific needs of children based on their social-economic status, area of residence, and other demographic characteristics that were identified as determinants of child malnutrition instead of using a general approach.
\end{abstract}

Keywords: Underweight, stunting, wasting, overweight, obesity, malnutrition, Kenya, Africa.

\section{INTRODUCTION}

Childhood malnutrition is linked to several developmental and health-related challenges. For example, stunting in early childhood is associated with poor physical and mental development, increased susceptibility to infections, increased morbidity and mortality, and increased risk of overweight and obesity in adulthood [1]. Similarly, severe acute malnutrition (SAM) during childhood has shown long-term negative effects on cognitive function resulting in children being less competitive academically as well as having lower self-esteem [2]. In particular, malnutrition during the first 1000 days of life - the period from conception to 2 years - is very critical as this period is considered the most important for neurological development [3]. Several studies in developed countries have shown that poor nutrition in the first 1000 days is associated with obesity and its comorbidities in later life $[4,5]$.

The determinants of childhood malnutrition are multifaceted and are influenced by individual, household, and community factors. The United Nations Child Education Fund (UNICEF) proposed a framework in 1990 that grouped the determinants of childhood malnutrition into 3 levels, a) immediate causes, b)

*Address correspondence to this author at the Department of Nutrition and Health Science, HB 542, Ball State University, Muncie, IN 47306, USA; Tel: 765-285-3758; E-mail: tnmbogori@bsu.edu underlying causes, and c) Basic causes [6]. The immediate causes are believed to be poor food intake and disease infections such as malaria, diarrhea, and pneumonia. The underlying determinants, mainly observed at the household level, include food insecurity, suboptimal caring capacity for mothers and children, and inadequate access to a safe and healthy environment like clean water and sanitation and health care facilities. At the basic level, these underlying determinates are influenced by resources available to the household and community and how the social, cultural, and political environments influence the distribution of these resources [7]. Many governmental and non-governmental based interventions are designed to mitigate the effects of childhood malnutrition by mainly targeting these determinants at national levels.

While progress has been made in improving the nutritional status of children in Kenya, it is important to note that levels of malnutrition remain high. A recent study showed that stunting, underweight, and wasting in children under the age of 5 years in Kenya decreased by 12,7 , and 3 percentage points respectively between 1998 and 2014 [8]. Studies have identified determinants of undernutrition in subSaharan Africa using nationally representative data [9]. The majority of these studies are done on children from birth to 5 years of age. Very few studies have been 
done specifically on children who are within the first 1000 days period despite the known importance of this period. Therefore, this study aimed to identify the determinants of childhood malnutrition in children 0-23 months old in Kenya.

\section{MATERIALS AND METHODS}

\section{Study Design and Sampling}

This was a secondary data analysis of the 2014/2015 Kenya Health Demographic Health Survey (KDHS). KDHS is a nationally representative crosssectional survey conducted every 5 years to determine the health and demographic characteristics of the population [10]. This survey utilized a cluster multistage sampling method where the primary sampling units were clusters drawn from the NASSEP $V$ (Fifth National Sample Survey and Evaluation Program) master sampling frame. This sampling frame contained 5360 clusters drawn by stratified probability sampling methodology from 96,251 enumeration areas (EAs) in the 2009 Kenya Population and Housing Census. 1612 clusters were selected in the first stage, with 995 and 617 being rural and urban, respectively. In the second stage, 25 households were selected from each cluster, yielding a total of 40,300 households representing Kenya's population. Data were collected from only the preselected households, and no replacement was allowed during data collection. Data were collected using an interviewer-administered questionnaire that was done by trained field staff. The response rate was $99 \%[10]$.

\section{Anthropometric Measurements and Nutritional Status}

Nutritional status was determined using weight and height measurements. Weight was measured using an electronic digital SECA scale and was measured to the nearest $100 \mathrm{~g}$. Very young children were weighed with their mother, and the scale allowed for automatic elimination of the mother's weight when measured standing on the scale with the child. Height measurements were taken using height/length Shorr boards manufactured by Shorr productions specifically for this study [10]. The recumbent length of children younger than 2 years was taken with children lying on the board. Nutrition specialists from partnering organizations conducted training on collecting anthropometric measurements where the trainees completed a standardization exercise measuring children, which was intended to determine and refine measurement accuracy and precision [10]. Height for
Age $Z$ scores (HAZ), Weight for Height $Z$ scores (WHZ), and BMI for age $Z$ scores (BAZ) was calculated using growth standards determined by the World Health organization in 2006. WHZ, HAZ, and BAZ were coded into wasting, stunting, and overweight/obesity, respectively. Stunting was coded as follows; HAZ scores >-1.99 normal, -2.99- -2.00 moderately stunted, and $<-3.00$ severely stunted. Wasting was coded as follows; WHZ scores $>2.00$ overweight, $-1.99-1.99$ normal, -2.99- -2.00 moderately wasted and <-3.00 severely wasted. Overweight and obesity were coded as follows; BAZ scores $<-2.00-1.99$, normal, 2.002.99 overweight, and $>3.0$ obese [11].

\section{Demographic and Social-Economic Variables}

Participants were categorized as either rural or urban based on their geographical location during data collection. Wealth index, a proxy for long-term household standard of living, was constructed using household asset data and generated through principal component analysis [10]. Education level was determined by responses to the question on the respondent's highest level of schooling. Literacy levels were determined by the individual's ability to read sentences provided by the interviewers. These standard sentences were written in the 17 main languages in Kenya. Respondents with primary education and lower were asked to read the sentences in languages they were most familiar with, and those with secondary and higher were assumed to be literate [10].

\section{Data Analysis}

Data were analyzed using IBM SPSS statistics 26. Descriptive statistics were used to determine the characteristics of the children and households used for this analysis. To determine the disparities between the social-economic variables and nutrition status, chisquare statistics were used. Significance was set at $p$ $<0.05$.

\section{RESULTS}

A total of 7,578 children aged $0-23$ months were included in this study, with $77.5 \%$ being $6-23$ months old. The majority were rural residents $(68.5 \%)$ and were in the poor and poorest wealth index categories $(56 \%)$. About $27.5 \%$ of the children came from households where the mother or caretaker was considered illiterate as they could neither read nor write. In addition, about $21.4 \%$ of the mothers or caretakers had no formal education. About $22.7 \%$, 
Table 1: Demographic Characteristics of the Participants $(n=7578)$

\begin{tabular}{|c|c|c|c|}
\hline & Characteristic & $\mathbf{n}$ & $\%$ \\
\hline \multirow{2}{*}{ Residence } & Urban & 2384 & 31.5 \\
\hline & Rural & 5194 & 68.5 \\
\hline \multirow{4}{*}{ Education level } & No education & 1618 & 21.4 \\
\hline & Primary & 3919 & 51.7 \\
\hline & Secondary & 1535 & 20.3 \\
\hline & Higher & 506 & 6.7 \\
\hline \multirow{2}{*}{ Household head } & Male & 5415 & 71.5 \\
\hline & Female & 2163 & 28.5 \\
\hline \multirow{5}{*}{ Literacy } & Cannot read at all & 2078 & 27.5 \\
\hline & Able to read-only parts of sentence & 742 & 9.8 \\
\hline & Able to read whole sentence & 4733 & 62.6 \\
\hline & No card with required language & 3 & 0 \\
\hline & Blind/visually impaired & 10 & 0.1 \\
\hline \multirow{5}{*}{ Wealth index } & Poorest & 2689 & 35.5 \\
\hline & Poorer & 1563 & 20.6 \\
\hline & Middle & 1251 & 16.5 \\
\hline & Richer & 1106 & 14.6 \\
\hline & Richest & 969 & 12.8 \\
\hline \multirow{2}{*}{ Sex of child } & Male & 3841 & 50.7 \\
\hline & Female & 3737 & 49.3 \\
\hline \multirow{4}{*}{ Nutritional status } & Stunting & 1717 & 22.7 \\
\hline & Wasting & 476 & 6.2 \\
\hline & Overweight & 366 & 4.8 \\
\hline & Obese & 100 & 1.3 \\
\hline
\end{tabular}

$6.2 \%, 4.8 \%$, and $1.3 \%$ were stunted, wasted, overweight, and obese, respectively. More descriptive characteristics of the participants are presented in Table 1.

The highest proportion of stunting was found among children from rural residences $(16.7 \%$ moderate and $7.8 \%$ severe) as compared to urban residences $(12.3 \%$ moderate and $6.5 \%$ severe $\%) \quad(p<0.0001)$. Similarly, wasting was significantly higher in children from rural $(4.7 \%$ moderate and $1.8 \%$ severe) as compared to urban ( $4.1 \%$ moderate and $1.6 \%$ severe) $(p=0.019)$. In contrast, overweight and obesity were higher in urban residents $(7.5 \%)$ as compared to rural residents $(5.5 \%)(p=0.006)$, as shown in Table 2.

As compared to children from poorer and poorest quintiles, those from a household of higher quintiles of wealth indices (richer and richest) had lower percentages of moderate and severe stunting (18.9\% and $12.4 \%$ vs. $27.8 \%$ and $25.1 \%)(p<0.0001)$ and moderate and severe wasting $(4.5 \%$ and $4.1 \%$ vs. $8.0 \%$ and $4.6 \%)(p<0.0001)$. However, more children were overweight and obese in the richer and richest categories compared to the poor and poorer wealth index categories $(p<0.0001)$. A full description of the relationship between wealth index and child nutrition status is shown in Table 3.

Significant differences were found between the nutritional status of children and the educational level of the household head. Children from household heads with secondary education and higher were less likely to be severely stunted than children from households with primary education or no education at all $(5.2 \%$ and $3.8 \%$ vs. $8.2 \%$ and $8.4 \%$ ). Similarly, a higher proportion of children who were wasted were from households where the heads had no education primary education. On the contrary, overweight and obesity were 
Table 2: Relationship between the Place of Residence (Urban vs. Rural) and Childhood Malnutrition in Children 0-23 Months Old in Kenya

\begin{tabular}{|c|c|c|c|c|c|}
\hline & & Urban n (\%) & Rural n (\%) & $x^{2}$ & P-value \\
\hline \multirow{3}{*}{ Stunting } & Normal weight & $1935(81.2)$ & $3926(75.6)$ & \multirow{3}{*}{30.21} & \multirow{3}{*}{$<0.0001$} \\
\hline & Moderate stunting & $293(12.3)$ & $865(16.7)$ & & \\
\hline & Severe stunting & $156(6.5)$ & $403(7.8)$ & & \\
\hline \multirow{3}{*}{ Wasting } & Normal weight & $2070(86.8)$ & $4561(87.8)$ & \multirow{3}{*}{9.99} & \multirow{3}{*}{0.019} \\
\hline & Moderate stunting & $98(4.1)$ & $246(4.7)$ & & \\
\hline & Overweight & $177(7.4)$ & $294(5.7)$ & & \\
\hline \multirow{4}{*}{ BMI for age } & Normal weight & $2081(87.3)$ & $4608(88.7)$ & \multirow{4}{*}{14.31} & \multirow{4}{*}{0.006} \\
\hline & Overweight & $137(5.7)$ & $229(4.4)$ & & \\
\hline & Obese & $43(1.8)$ & $57(1.1)$ & & \\
\hline & Underweight & $123(5.2)$ & $300(5.8)$ & & \\
\hline
\end{tabular}

Table 3: Relationship between Wealth Index and Childhood Malnutrition in Children 0-23 Months Old in Kenya

\begin{tabular}{|c|c|c|c|c|c|c|c|c|}
\hline & & $\begin{array}{c}\text { Poorest } \\
\text { n (\%) }\end{array}$ & Poorer n (\%) & $\begin{array}{c}\text { Middle } \\
\text { n (\%) }\end{array}$ & $\begin{array}{l}\text { Richer } \\
\text { n (\%) }\end{array}$ & $\begin{array}{c}\text { Richest } \\
\text { n (\%) }\end{array}$ & $x^{2}$ & $\mathbf{P}$ \\
\hline \multirow{2}{*}{ Stunting } & Normal weight & $1940(72.1)$ & $1170(74.9)$ & 1005 (80.3) & $897(81.1)$ & $849(87.6)$ & \multirow{2}{*}{130.00} & \multirow{2}{*}{$<0.0001$} \\
\hline & Severe stunting & $264(9.8)$ & $110(7.0)$ & $76(6.1)$ & $76(6.9)$ & $33(3.4)$ & & \\
\hline \multirow{3}{*}{ Wasting } & Normal weight & 2355 (87.6) & 1396 (89.3) & 1087 (86.9) & $972(87.9)$ & $821(84.7)$ & \multirow{3}{*}{126.72} & \multirow{3}{*}{$<0.0001$} \\
\hline & Severe wasting & $66(2.5)$ & $22(1.4)$ & $21(1.7)$ & $14(1.3)$ & $9(0.9)$ & & \\
\hline & Overweight & $93(3.5)$ & $95(6.1)$ & $90(7.2)$ & $89(8.0)$ & $104(10.7)$ & & \\
\hline \multirow{2}{*}{$\begin{array}{l}\text { BMl for } \\
\text { age }\end{array}$} & Normal weight & $2392(89.0)$ & $1407(90.0)$ & 1098 (87.8) & $970(87.7)$ & $822(84.8)$ & \multirow{2}{*}{135.19} & \multirow{2}{*}{$<0.0001$} \\
\hline & Overweight & $73(2.7)$ & $70(4.5)$ & $70(5.6)$ & $76(6.9)$ & $77(7.9)$ & & \\
\hline
\end{tabular}

Table 4: Relationship between Education Status and Childhood Malnutrition in Children 0-23 Months Old in Kenya

\begin{tabular}{|c|c|c|c|c|c|c|c|}
\hline & & No education $\mathrm{n}(\%)$ & Primary n (\%) & Secondary $\mathrm{n}(\%)$ & Higher n (\%) & $x^{2}$ & P-value \\
\hline \multirow{2}{*}{ Stunting } & Normal weight & $1224(75.6)$ & $2944(75.1)$ & $1260(82.1)$ & $433(85.6)$ & \multirow{2}{*}{55.78} & \multirow{2}{*}{$<0.0001$} \\
\hline & Severe stunting & $132(8.2)$ & $328(8.4)$ & $80(5.2)$ & $19(3.8)$ & & \\
\hline \multirow{3}{*}{ Wasting } & Normal weight & $1373(84.9)$ & $3492(89.1)$ & $1340(87.3)$ & $426(84.2)$ & \multirow{3}{*}{165.14} & \multirow{3}{*}{$<0.0001$} \\
\hline & Severe wasting & $54(3.3)$ & $59(1.5)$ & $16(1.0)$ & $13(0.6)$ & & \\
\hline & Overweight & $57(3.5)$ & $226(5.8)$ & $123(8.0)$ & $65(12.8)$ & & \\
\hline \multirow{2}{*}{ BMI for age } & Normal weight & $1405(86.8)$ & $3520(89.8)$ & $1343(87.5)$ & $421(83.2)$ & \multirow{2}{*}{191.12} & \multirow{2}{*}{$<0.0001$} \\
\hline & Overweight & $36(2.2)$ & $168(4.3)$ & $106(6.9)$ & $56(11.1)$ & & \\
\hline
\end{tabular}


Table 5: Relationship between Literacy Status and Childhood Malnutrition in Children 0-23 Months Old

\begin{tabular}{|c|c|c|c|c|c|c|c|c|}
\hline & & $\begin{array}{c}\text { Cannot } \\
\text { read at all } \\
\mathbf{n}(\%)\end{array}$ & $\begin{array}{c}\text { Only parts } \\
\text { of } \\
\text { sentence } n \\
(\%)\end{array}$ & $\begin{array}{c}\text { Whole } \\
\text { sentence } \\
\text { n (\%) }\end{array}$ & $\begin{array}{c}\text { *No card } \\
\text { n (\%) }\end{array}$ & $\begin{array}{c}\text { Blind/visually } \\
\text { impaired } \\
n(\%)\end{array}$ & $x^{2}$ & p-value \\
\hline \multirow{3}{*}{ Stunting } & Normal weight & $1545(74.4)$ & $549(74.0)$ & $3746(79.1)$ & $2(66.7)$ & $9(90.0)$ & \multirow{3}{*}{30.57} & \multirow{3}{*}{$<0.0001$} \\
\hline & Moderate stunting & $346(16.7)$ & $124(16.7)$ & $685(14.5)$ & $1(33.3)$ & $1(10.0)$ & & \\
\hline & Severe stunting & $187(9.0)$ & $69(9.3)$ & $302(6.4)$ & $0(0.0)$ & $0(0.0)$ & & \\
\hline \multirow{4}{*}{ Wasting } & Normal weight & $1779(85.6)$ & 649 (87.5) & $4185(88.4)$ & $1(33.3)$ & $8(80.0)$ & \multirow{4}{*}{159.10} & \multirow{4}{*}{$<0.0001$} \\
\hline & Moderate wasting & $157(7.6)$ & $30(4.0)$ & $152(3.2)$ & $2(66.7)$ & $1(10.0)$ & & \\
\hline & Severe wasting & $66(3.2)$ & $11(1.5)$ & $54(1.1)$ & $0(0.0)$ & $1(10.0)$ & & \\
\hline & Overweight & $76(3.7)$ & $52(7.0)$ & $342(7.2)$ & $0(0.0)$ & $0(0.0)$ & & \\
\hline \multirow{4}{*}{$\begin{array}{l}\text { BMl for } \\
\text { age }\end{array}$} & Normal weight & $1813(87.2)$ & $661(89.1)$ & 4197 (88. 7) & $1(33.3)$ & $8(80.0)$ & \multirow{4}{*}{152.59} & \multirow{4}{*}{$<0.0001$} \\
\hline & Overweight & $56(2.7)$ & $35(4.7)$ & $275(5.8)$ & $0(0.0)$ & $0(0.0)$ & & \\
\hline & Obese & $15(0.7)$ & $11(1.5)$ & $73(1.5)$ & $0(0.0)$ & $0(0.0)$ & & \\
\hline & Underweight & $194(9.4)$ & $35(4.7)$ & $188(4.0)$ & $2(66.7)$ & $2(20.0)$ & & \\
\hline
\end{tabular}

${ }^{*}$ Respondents were not familiar with any of the 17 languages on the cards

associated with households with household heads with secondary education and higher. The relationship between education status and nutritional status is summarized in Table 4.

Children from households where the respondent was illiterate or had lower literacy levels had statistically significantly higher undernutrition levels than those with higher literacy levels. For example, severe stunting was found in $9 \%$ of children from households with parents or caretakers who could not read or write compared to $6.4 \%$ of children from families with parents who could read and write the whole sentences $(p<0.005)$. Overweight and obesity were also more prevalent in children from households where the parents or caretakers with higher literacy levels, as shown in Table 5.

\section{DISCUSSION}

The purpose of this study was to identify the demographic and social-economic characteristics, particularly in the area of residence, wealth status, education, and literacy levels, associated with the nutritional status of children less than 2 years old in Kenya. Children living in households, from rural areas, with lower wealth index, low education attainment, and low literacy levels were found to have a significantly higher prevalence of stunting, wasting, and underweight. In contrast, overweight and obesity, although still low in prevalence among children in this age group, was found to be significantly higher in urban, wealthier, higher education, and higher literacy level households. Similar findings have been reported in studies using demographic health surveys in developing countries [12] and especially in subSaharan African countries [13, 14] among children 0-5 years old.

All indicators of childhood malnutrition except overweight and obesity were significantly higher in rural areas than in urban areas. Previous studies have had conflicting findings on whether the rural-urban effects on child malnutrition persist when other socialeconomic variables such as education level and income are controlled $[15,16]$. Some of these studies found that undernutrition in urban areas remained the same or was higher than in rural areas $[17,18]$ when other social-economic variables were controlled. The reason children in urban areas tend to show better nutrition outcomes has been attributed to women's higher education status, availability of clean water and sanitation, higher income, and increase in women decision making capability [19], factors that have been shown to positively influence child nutritional status [2022]. Kimani-Murage et al. (2014) found that the gap between urban and rural residence in respect to health outcomes was narrowing, and they attributed this to the majority of urban residents living in informal settlements that have poor access to water and sanitation, job opportunities, and inadequate health services [23]. Therefore, the place of residence may not independently influence the nutritional status of children when other factors such as education level and wealth status are put into consideration. 
The wealth index is a composite measure of a household living standard, and it is used in countries where reliable measurements of income and expenditure that can be used to estimate household economic status are missing. Household assets, nature of materials used for housing, and access to water and sanitation facilities variables are used to derive the wealth index using the methodology proposed by Filmer and Pritchett [24]. Therefore, children from households with a higher wealth index are expected to have better nutrition status, which has been reported in many studies worldwide $[17,25,26]$. Tasmin et al. (2017), in their study, reported that lack of water availability, lack of latrine in the home, and poor roofing materials were associated with increased odds of being underweight in children (OR: 5.00, 2.70 and 4.00 respectively) [27]. Households with a higher wealth index are more likely to have a higher education status of the household members because education enhancement leads to better job placement and hence higher income.

Educational level and literacy status, although closely related, were measured independently in this study. Respondents who had secondary education or higher were considered literate, and literacy level was then measured in those reporting to have primary education or lower. Many studies have highlighted the importance of maternal education level on the nutritional status of children, especially children 5 years and younger [28, 29]. Women with higher education levels are likely to have more income, be more food secure, and have access to sufficient health care for their children [30]. We can therefore anticipate that this was the case in this study.

Strategies to reduce malnutrition in children in Kenya are based on the Sustainable Development Goals (SDGs) agreed on by the United Nations in 2015 [31]. Specifically, programs and projects target SDGs such as poverty and hunger eradication, improved education quality, improved health quality, clean water and sanitation, and reduction in inequalities. In Kenya, significant progress has been made at the policy level in working towards achieving the SDGs through developing the Kenya Vision 2030 blueprint [32]. However, the impacts of these projects at household and individual levels are yet to be documented. Policymakers and researchers need to start publishing the impacts of these interventions on childhood nutritional status so that governments and their development partners can make more informed decisions on where to spend most of their resources.

The main strength of this study was the use of nationally representative data that ensured equal representation of the Kenyan population. However, there were few limitations in the study. First, this was secondary data analysis, and therefore not all variables of interest were available for analysis. Another limitation is that the data was collected in 2014, which is a little dated considering the current COVID -19 pandemic that may have modified some of the determinants discussed here. However, this was the most recent data set available that is nationally representative. Future studies need to use more current data that may reflect recent changes that could have occurred and the impact of the COVID-19 pandemic on the progress in improving the nutritional status of children in Kenya.

\section{CONCLUSION}

Although improvements in the nutritional status of children in Kenya have been observed, levels of undernutrition especially stunting, remain high. Many studies focus on children 0-5 years old, and only a few give attention to the subgroup within the first 1000 days of life (0-23 months). Therefore, this study sought to focus on that age group. It was found that children (023 months old) from rural residences and households with lower social-economic status were more likely to be undernourished than their counterparts from urban residences and higher social, economic status households. Several programs and projects have been initiated to improve the nutritional status of children in Kenya at the policy level. However, data regarding the impact of these interventions on reducing malnutrition in children at the household or individual level is still scarce. Future studies should look at the reach and impact of government and non-governmental interventions on children's nutritional status based on their demographic and social-economic characteristics. This then will inform researchers and policymakers on where to input more resources to continue decreasing the levels of childhood malnutrition in Kenya.

\section{ETHICS APPROVAL}

Not required as this was a secondary data analysis.

\section{CONFLICT OF INTEREST}

No conflict of interest to report. 


\section{REFERENCES}

[1] De Sanctis V, Soliman A, Alaaraj N, Ahmed S, Alyafei F, Hamed N. Early and long-term consequences of nutritional stunting: from childhood to adulthood. Acta Biomed 2021; 92(1): e2021168-e.

[2] Mwene-Batu P, Bisimwa G, Baguma M, et al. Long-term effects of severe acute malnutrition during childhood on adult cognitive, academic and behavioral development in fragile African countries: The Lwiro cohort study in the Democratic Republic of the Congo. PLoS One 2020; 15(12): e0244486. https://doi.org/10.1371/journal.pone.0244486

[3] Schwarzenberg SJ, Georgieff MK. Advocacy for improving nutrition in the first 1000 days to support childhood development and adult health. Pediatrics 2018; 141(2): e20173716.

https://doi.org/10.1542/peds.2017-3716

[4] Blake-Lamb TL, Locks LM, Perkins ME, Woo Baidal JA, Cheng ER, Taveras EM. Interventions for childhood obesity in the first 1,000 days a systematic review. Am J Prev Med 2016; 50(6): 780-9.

https://doi.org/10.1016/j.amepre.2015.11.010

[5] Baidal JA, Locks LM, Cheng ER, Blake-Lamb TL, Perkins ME, Taveras EM. Risk factors for childhood obesity in the first 1,000 days: a systematic review. Am J Prev Med 2016; 50(6): 761-79.

https://doi.org/10.1016/j.amepre.2015.11.012

[6] Reinhardt K, Fanzo J. Addressing chronic malnutrition through multi-sectoral, sustainable approaches: a review of the causes and consequences. Front Nutr 2014; 1 : 13. https://doi.org/10.3389/fnut.2014.00013

[7] ljarotimi OS. Determinants of childhood malnutrition and consequences in developing countries. Curr Nutr Rep 2013; 2(3): 129-33. https://doi.org/10.1007/s13668-013-0051-5

[8] Mbogori $\mathrm{T}$, Kimmel $\mathrm{K}$, Zhang $\mathrm{M}$, Kandiah J, Wang $\mathrm{Y}$. Nutrition transition and double burden of malnutrition in Africa: A case study of four selected countries with different social-economic development. AIMS Public Health 2020; 7(3): 425.

https://doi.org/10.3934/publichealth.2020035

[9] Chirwa EW, Ngalawa HP. Determinants of child nutrition in Malawi. S Afr J Econ 2008; 76(4): 628-40.

https://doi.org/10.1111/j.1813-6982.2008.00212.x

[10] Kenya National Bureau of Statistics, Ministry of Health/Kenya, National AIDS Control Council/Kenya, Kenya Medical Research Institute, National Council for Population and Development/Kenya. Kenya Demographic and Health Survey 2014. Rockville, MD, USA 2015.

[11] World Health Organization. WHO child growth standards: length/height-for-age, weight-for-age, weight-for-length, weight-for-height and body mass index-for-age: methods and development: World Health Organization 2006.

[12] Van de Poel E, Hosseinpoor AR, Speybroeck N, Van Ourti T, Vega J. Socioeconomic inequality in malnutrition in developing countries. Bull World Health Organ 2008; 86(4): 282-91.

https://doi.org/10.2471/BLT.07.044800

[13] Ekholuenetale M, Tudeme G, Onikan A, Ekholuenetale CE. Socioeconomic inequalities in hidden hunger, undernutrition, and overweight among under-five children in 35 sub-Saharan Africa countries. J Egypt Public Health Assoc 2020; 95(1): 9. https://doi.org/10.1186/s42506-019-0034-5

[14] Asuman D, Ackah CG, Fenny AP, Agyire-Tettey F. Assessing socioeconomic inequalities in the reduction of child stunting in sub-Saharan Africa. J Public Health 2020; 28(5): 563-73. https://doi.org/10.1007/s10389-019-01068-2
[15]

Fotso J-C. Urban-rural differentials in child malnutrition: Trends and socioeconomic correlates in sub-Saharan Africa. Health \& Place 2007; 13(1): 205-23. https://doi.org/10.1016/j.healthplace.2006.01.004

[16] Van de Poel E, O'Donnell O, Van Doorslaer E. Are urban children really healthier? Evidence from 47 developing countries. Soc Sci Med 2007; 65(10): 1986-2003. https://doi.org/10.1016/j.socscimed.2007.06.032

[17] Hong SA, Winichagoon $\mathrm{P}$, Khang $\mathrm{Y}-\mathrm{H}$. Rural-urban differences in socioeconomic inequality trends for double burden of malnutrition in Thailand 2005-2016. Eur J Clin Nutr 2020; 74(3): 500-8 https://doi.org/10.1038/s41430-019-0510-1

[18] Ameye $\mathrm{H}$, De Weerdt J. Child health across the rural-urban spectrum. World Dev 2020; 130: 104950. https://doi.org/10.1016/j.worlddev.2020.104950

[19] Smith LC, Ruel MT, Ndiaye A. Why is child malnutrition lower in urban than in rural areas? Evidence from 36 developing countries. World Dev 2005; 33(8): 1285-305.

\section{https://doi.org/10.1016/j.worlddev.2005.03.002}

[20] Mishra VK, Retherford RD. Women's education can improve child nutrition in India. Natl Fam Health Surv Bull 2000(15): 14.

[21] Mshida HA, Kassim N, Mpolya E, Kimanya M. Water sanitation, and hygiene practices associated with nutritional status of under-five children in semi-pastoral communities Tanzania. Am J Trop Med Hyg 2018; 98(5): 1242-9. https://doi.org/10.4269/ajtmh.17-0399

[22] Ohonba A, Ngepah N, Simo-Kengne B. Maternal education and child health outcomes in South Africa: A panel data analysis. Dev South Afr 2019; 36(1): 33-49. https://doi.org/10.1080/0376835X.2018.1456908

[23] Kimani-Murage EW, Fotso JC, Egondi T, et al. Trends in childhood mortality in Kenya: The urban advantage has seemingly been wiped out. Health \& Place 2014; 29: 95-103. https://doi.org/10.1016/j.healthplace.2014.06.003

[24] Filmer D, Pritchett LH. Estimating wealth effects without expenditure data--or tears: an application to educational enrollments in states of India. Demography 2001; 38(1): 11532. https://doi.org/10.1353/dem.2001.0003

[25] Hong R, Mishra V. Effect of wealth inequality on chronic under-nutrition in Cambodian children. J Health Popul Nutr 2006; 24(1): 89-99.

https://doi.org/10.1186/1475-9276-5-15

[26] Hong R, Banta JE, Betancourt JA. Relationship between household wealth inequality and chronic childhood undernutrition in Bangladesh. Int J Equity Health 2006; 5(1): 15.

[27] Tasnim T, Dasvarma G, Mwanri L. Housing conditions contribute to underweight in children: an example from rural villages in southeast Sulawesi, Indonesia. J Prev Med Public Health 2017 ; 50(5): 328-35. https://doi.org/10.3961/jpmph.17.046

[28] Nepali S, Simkhada P, Davies I. Trends and inequalities in stunting in Nepal: a secondary data analysis of four Nepal demographic health surveys from 2001 to 2016. BMC Nutr 2019; 5(1): 19. https://doi.org/10.1186/s40795-019-0283-x

[29] Khan S, Zaheer S, Safdar NF. Determinants of stunting underweight and wasting among children $<5$ years of age: evidence from 2012-2013 Pakistan demographic and health survey. BMC Public Health 2019; 19(1): 358. https://doi.org/10.1186/s12889-019-6688-2

[30] Mekonnen AG, Odo DB, Nigatu D, Sav A, Abagero KK. Women's empowerment and child growth faltering in Ethiopia: evidence from the Demographic and Health Survey. BMC Women's Health 2021; 21(1): 42. https://doi.org/10.1186/s12905-021-01183-x 
[31] United Nations, Transforming our world: the 2030 Agenda for Sustainable Development 2015 [cited 2021 June 6]; Available from: https: //sdgs.un.org/goals.
[32] GOK, Kenya Vision 2030: A Global Competitive and Prosperous Kenya, Ministry of Planning and National Development and National Economic and Social Council (NESC, Nairobi, 2007).

https://doi.org/10.6000/1929-4247.2021.10.03.1

(C) 2021 Mbogori and Muriuki; Licensee Lifescience Global.

This is an open access article licensed under the terms of the Creative Commons Attribution Non-Commercial License (http://creativecommons.org/licenses/by-nc/3.0/) which permits unrestricted, non-commercial use, distribution and reproduction in any medium, provided the work is properly cited. 